\title{
Haemostatic defects in cyanotic congenital heart disease
}

\author{
PER HENRIKSSON, GUNILLA VÄRENDH, AND NILS-RUNE LUNDSTRÖM \\ From the Department of Paediatrics and Coagulation Laboratory, University of Lund, Allmänna \\ Sjukhuset, Malmö, and Cardiologic Division of the Department of Paediatrics, University of Lund, \\ Lund, Sweden
}

SUMMARY An investigation of defects of the haemostatic mechanism in 41 children with cyanotic congenital heart disease concluded that such abnormalities were common and normally involved factors synthesised in the liver, that is the vitamin $\mathrm{K}$ dependent factors (prothrombin, factors VII and IX) and factor V. No evidence was found of activation of the coagulation or fibrinolytic systems. The defects can be explained by deficient synthesis resulting from systemic hypoxia as well as from sluggishness of the local microcirculation caused by high blood viscosity. Vitamin $\mathrm{K}$ parenterally had no demonstrable effect. Replacement of these factors, possibly combined with measures to improve the microcirculation, therefore, appears to be the appropriate treatment.

Over the past 25 years multiple defects of haemostasis involving platelet function and the coagulation and fibrinolytic systems have been reported in children with cyanotic congenital heart disease. These have been reviewed by Ekert et al. (1970), Maurer (1972), and Wedemeyer et al. (1972). Cardiac catheterisation and surgery are prone to be complicated by thrombosis, haemorrhage, or both (Bahnson and Ziegler, 1950; Berthrong and Sabiston, 1951; Hartmann, 1952), and cerebral lesions are an additional hazard (Cottrill and Kaplan, 1973; Terplan, 1973).

This study attempts to define these haemostatic abnormalities and to ascertain whether they are caused by activated coagulation within the circulation, by activated fibrinolysis, or by disordered production of coagulation factors.

\section{Patients}

Studies were perfomed on 41 cyanotic patients (25 male and 16 female). Their ages ranged from 1 month to 24 years (median 1 year 6 months). Fourteen had Fallot's tetralogy, 21 transposition of the great arteries, and 6 other complex cyanotic cardiac malformations.

\section{BLOOD SAMPLING}

Blood was obtained from a central artery or vein via the polyethylene catheter used for angiocardiography. The silicone technique was used and plasma

Received for publication 7 November 1977 prepared as previously described (Nilsson et al., 1957). Sodium citrate, 3.8 per cent, in a dilution of 1 to 10 was used as anticoagulant. The results were corrected for haematocrit.

The normal ranges were adjusted to the dilution of plasma. Powdered EDTA was added to blood used for measurement of viscosity.

\section{Methods}

Factors II, VII, and X, factor V, factor VIII activity (F VIII:C), factor IX activity, and platelet counts were determined as previously described (Nilsson et al., 1961). Factor VIII antigen (F VIIIR:Ag) was determined with Laurell's electroimmunoassay technique (Holmberg and Nilsson, 1973). Fibrinogen was measured as described by Nilsson and Olow (1962) and with the immunochemical method of Karaca et al. (1971). Fibrinolytic activity was measured on unheated bovine fibrin plates as described by Nilsson and Olow (1962). Plasminogen was determined by an immunochemical method (Ganrot and Niléhn, 1968). The ethanol gelation test described by Godal et al. (1971) was used as a test for fibrin monomers. Fibrin/fibrinogen degradation products were determined with the immunochemical method of Niléhn (1967). The determinations of fibrin/ fibrinogen degradation products were made on serum obtained from blood collected in tubes containing thrombin and epsilon amino caproic acid. Inhibitors of the fibrinolytic system were determined as described previously (Hedner et al., 
1970). Platelet morphology was studied in a phase contrast microscope. Platelet turnover was estimated with the aid of ${ }^{51} \mathrm{Cr}$-labelled isologous platelets (Abrahamsen, 1968). Fibrinogen survival was studied with human fibrinogen (AB Kabi, Sweden) labelled with ${ }^{125} \mathrm{I}$, essentially by the technique of McFarlane (1956). Antithrombin III was determined according to the method described by Abildgaard et al. (1970). Fibrinolytic activity in the vessel wall was estimated by Pandolfi's modification of Todd's histochemical method (Pandolfi et al., 1972) on vein biopsy specimens obtained from the chest wall during operation. Whole blood viscosity was measured at $37^{\circ} \mathrm{C}$ with a Wells-Brookfield cone plate microviscometer (Wells et al., 1961). The haematocrit was measured in duplicate with a micromethod. Stained dry blood films were examined for fragmented red cells.

\section{Results}

Thrombocytopenia (below $125 \times 10^{9} / 1$ ) was found in 6 of the 41 patients, including 4 with a haematocrit of 80 per cent or more (Fig. 1). Factors II, VII, and $X$ were low in 35 of the patients (Fig. 2) and vitamin $\mathrm{K}$ (Konakion, Roche, $10 \mathrm{mg}$ intravenously) had no effect on the levels in 10 patients tested. Factor IX was abnormally low in 11 of 22 patients studied (Fig. 2). Factor $\mathrm{V}$ was low in 21 of the 41 patients (Fig. 3). Factor VIII:C and factor VIIIR: $\mathrm{Ag}$ were normal or increased. Fibrinogen determined by the clot method was decreased in 5 of 40 patients (Fig. 3). Fibrinogen determined immunologically was normal. Fibrinolytic activity on fibrin plates was increased in 3 out of 36 patients examined.

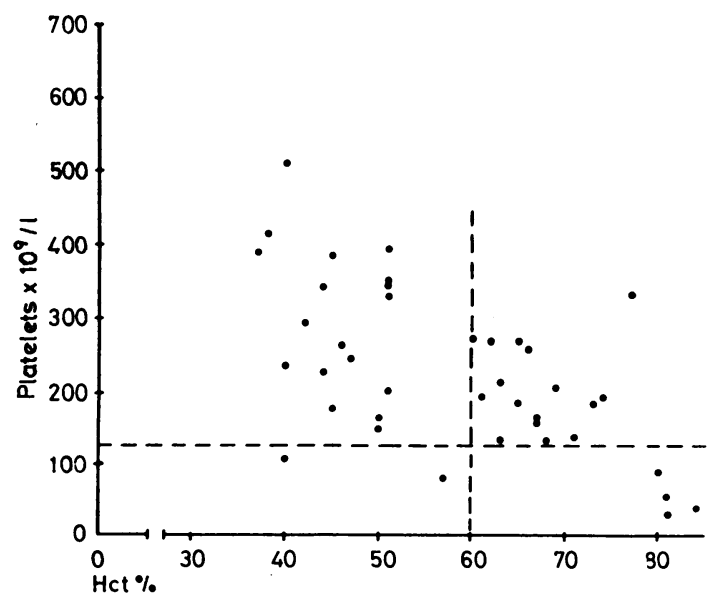

Fig. 1 Relation between platelet counts and haematocrit.

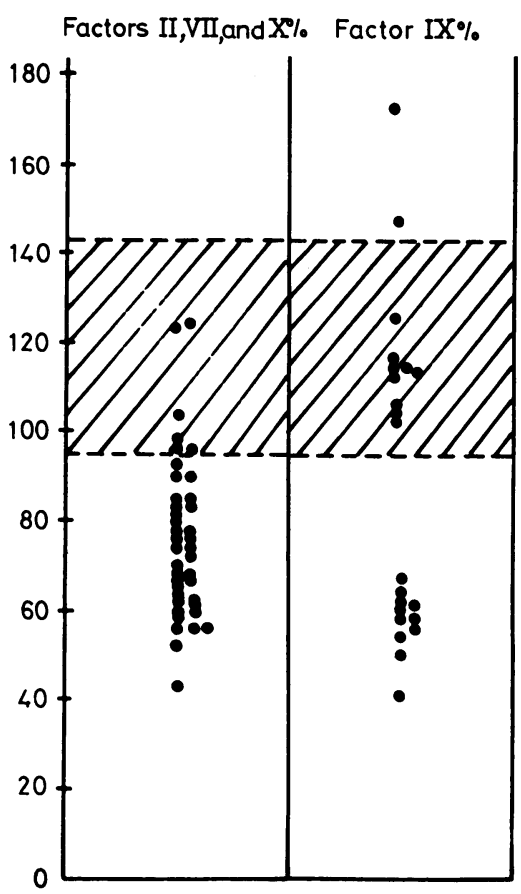

Fig. 2 The distribution of factors II, VII, and $X$ and of factor IX. Shaded area denotes normal range.

Fibrin/fibrinogen degradation products occurred in small amounts in 9 of the 41 patients (range 6 to 15 $\mathrm{mg} / 1$ ). Plasminogen, $\alpha_{2}$-macroglobulin, and anti-
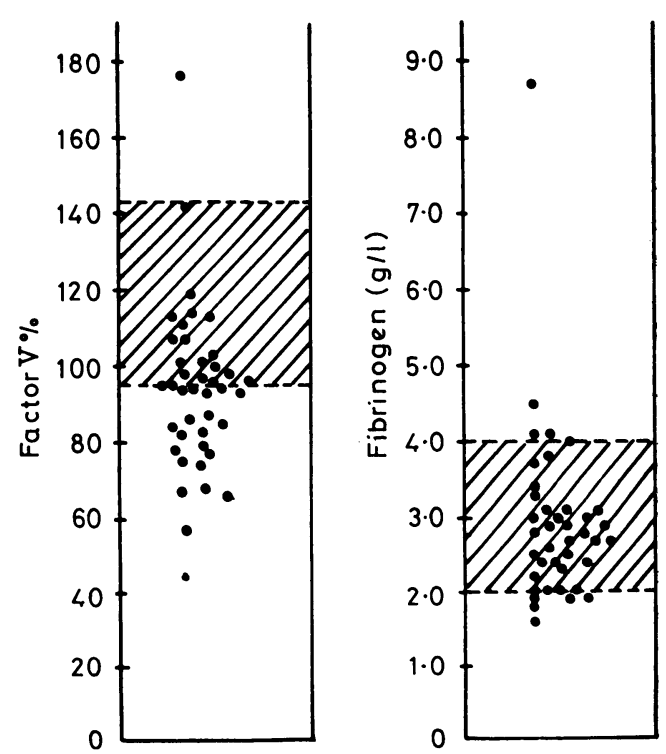

Fig. 3 The distribution of factor $V$ and fibrinogen. Shaded area denotes normal range. 


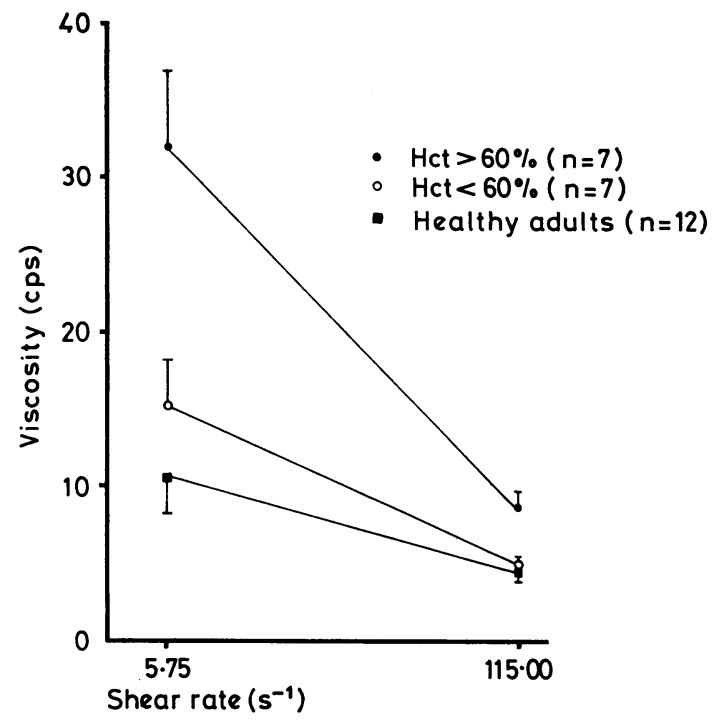

Fig. 4 Whole blood viscosity in patients with haematocrits above 60 per cent (O), below 60 per cent (O), and healthy adults ( $\square$ ).

thrombin III were within normal limits. Of 36 patients examined with the ethanol gelation test 3 showed positive results, but 2 of these later became negative. No fragmented red cells were found in 24 patients studied. The appearance of the platelets, including their spontaneous aggregation, adhesion to glass surface, and spreading phenomenon, was normal in 7 patients examined, 4 of them having a haematocrit above 60 per cent. Platelet kinetics and fibrinogen kinetics were studied simultaneously in 5 patients and fibrinogen kinetics alone in 1 . The platelet turnover was normal (half-life 3.5 to 4.0 days) in all the 5 patients. The fibrinogen half-life ranged from 1.5 to 3.4 days, mean 2.4 days (normal value found with the same preparation in 8 healthy adults: $3 \cdot 6 \pm 0.4$ days). Fibrinolytic activity of the vessel walls in vein biopsy specimens from 8 patients ranged from $5 \cdot 5$ to 9.0 arbitrary units (mean 7.3 units, $S D \pm 1.4$ ) (values found in 57 healthy children aged 1 month to 13 years: 6.9 units, $S D \pm 1 \cdot 7$ ).

Measurements of the viscosity of the blood in 14 patients are given in Fig. 4.

No difference was found in platelet count, fibrinogen, factors II, VII, and X, or factor V between patients above and below 3 years of age.

\section{Discussion}

Multiple defects in the haemostatic mechanism in patients with cyanotic congenital heart disease were found, mainly low levels of the vitamin $\mathrm{K}$ dependent factors, as indicated by low factors II, VII, and X ( $85 \%$ of the patients) and low factor IX $(50 \%)$. In addition, factor $\mathrm{V}$ was low in 50 per cent of the patients. Thrombocytopenia (below $125 \times 10^{9} / 1$ ) was found in only 15 per cent and was associated with high haematocrit levels (Fig. 1): although there is general agreement that such changes occur, opinions differ as to how they should be interpreted. Several workers believe that the abnormalities are caused by activated coagulation within the circulation (Ferencz, 1960; Kontras et al., 1966; Dennis et al., 1967; McKay, 1969; Bleyl and Höpker, 1970; Komp and Sparrow, 1970; Perlick et al., 1971; Ihenacho et al., 1973; Inglis et al., 1975); others by increased fibrinolysis (Gans and Krivit, 1962; Brodsky et al., 1969; Gralnick, 1970; Pike et al., 1975); and some by impaired production of the factors in question (O'Neill and Hutton, 1966; Johnson et al., 1968; Ekert et al., 1970; Iölster, 1970; Maurer, 1972; Wedemeyer et al., 1972). The normal platelet survival and the normal platelet morphology in our patients do not lend support to the hypothesis of increased consumption. A shortened platelet life-span has, however, been shown by other workers (Kummer et al., 1964; Wedemeyer and Lewis, 1973; Goldschmidt et al., 1974; Waldman et al., 1975). The thrombocytopenia might be explained by a hypoxic inhibition of platelet production (Gross et al., 1968). The absence of demonstrable fragmented red cells argues against fibrin deposition within the vessels. Fibrin/fibrinogen degradation products appeared in very small amounts in 25 per cent of the patients. Increased fibrinolytic activity was found in a few patients only, but the plasminogen concentrations were normal and the fibrinogen concentration was decreased in only 13 per cent. Yet the fibrinogen half-life was slightly shortened, while the platelet half-life measured at the same time was normal, indicating an increased catabolic rate of fibrinogen rather than a conversion to fibrin. No discrepancy was found between F VIII:C and F VIIIR:Ag (Henriksson and Holmberg, 1978). F XIII was normal (Hedner et al., 1975) and AT III as well as the $\alpha_{2} \mathrm{M}$ were normal. The overall picture, then, suggests that intravascular proteolytic activity with activation of the coagulation and/or the fibrinolytic systems is unlikely to be a cause of the haemostatic disturbances in these patients. This raises doubts whether heparin or fibrinolytic inhibitors are of value.

Low levels were found only of those factors known to be synthesised in the liver, that is prothrombin, factor $V$, and factor IX. Thus the abnormality is more consistent with that seen in 
impaired liver function. Evidence of liver damage in hypoxia has been presented by Ghosh and Emery (1973) and has also been discussed by Wedemeyer et al. (1972). The appearance of fibrin/fibrinogen degradation products in low concentrations could be explained by reduced elimination consequent upon reticuloendothelial dysfunction. Low levels of factors II, VII, and X could not be corrected by parenteral administration of vitamin $\mathrm{K}$; this is consistent with the observation that hypoxic liver damage prevents the synthesis of prothrombin complex from vitamin $\mathrm{K}$ (Markarian et al., 1967; Appleyard and Cottom, 1970). Goldschmidt (1970), however, did note a rise in prothrombin complex after administration of vitamin K. According to Isacson and Nilsson (1972) patients with recurrent thrombosis often have a reduced fibrinolytic activity in their vessel walls. Our patients were normal in this respect. Thrombotic complications might, therefore, be explained on haemorheological grounds, such as the high blood viscosity reported by Kontras et al. (1970), by Ohshima (1976), and also found in our patients.

If impaired production of coagulation factors and platelets is, in fact, the cause of the multiple haemostatic defects in patients with cyanotic congenital heart disease, it may be worth trying preoperative replacement therapy with platelets and preparations of factor IX concentrates, such as Preconativ (Kabi, Sweden), which also contains prothrombin and factor VII and is not thrombogenic (Hedner et al., 1976), together with methods to improve the microcirculation.

This work was supported by grants from the Swedish Medical Research Council and AnnaLisa och Sven-Erik Lundgrens stiftelse för medicinsk forskning.

\section{References}

Abildgaard, U., Gravem, K., and Godal, H. C. (1970). Assay of progressive antithrombin in plasma. Thrombosis et Diathesis Haemorrhagica, 24, 224-229.

Abrahamsen, A. F. (1968). A modification of the technique for ${ }^{51} \mathrm{Cr}$ labelling of blood platelets giving increased circulating platelet radioactivity. Scandinavian fournal of Haematology, 5, 53-63.

Appleyard, W. J., and Cottom, D. G. (1970). Effect of asphyxia on thrombotest values in low birth weight infants. Archives of Disease in Childhood, 45, 705-707.

Bahnson, H. T., and Ziegler, R. F. (1950). A consideration of the causes of death following operation for congenital heart disease of the cyanotic type. Surgery, Gynecology, and Obstetrics, 90, 60-76.

Berthrong, M., and Sabiston, D. C., Jr. (1951). Cerebral lesions in congenital heart disease. Bulletin of the fohns Hopkins Hospital, 89, 384-401.

Bleyl, U., and Höpker, W. W. (1970). Disseminierte intravasale Gerinnung und pulmonale hyaline Membranen bei

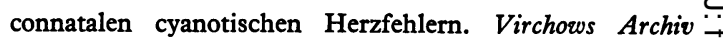
Abteilung A. Pathologische Anatomie, 350, 225-239.

Brodsky, I., Gill, D. N., and Lusch, C. J. (1969). Fibrinolysis in congenital heart disease. Preoperative treatment with $\epsilon$-aminocaproic acid. American fournal of Clinical Pathology, 51, 51-57.

Cottrill, C. M., and Kaplan, S. (1973). Cerebral vascular $\stackrel{\nabla}{\overparen{D}}$ accidents in cyanotic congenital heart disease. American Fournal of Diseases of Children, 125, 484-487.

Dennis, L. H., Stewart, J. L., and Conrad, M. E. (1967). Heparin treatment of haemorrhagic diathesis in cyanotic congenital heart-disease. Lancet, 1, 1088-1089.

Ekert, H., Gilchrist, G. S., Stanton, R., and Hammond, D. (1970). Hemostasis in cyanotic congenital heart disease. Fournal of Pediatrics, 76, 221-230.

Ferencz, C. (1960). The pulmonary vascular bed in tetralogy it of Fallot. I. Changes associated with pulmonary stenosis. $\rightarrow$ Bulletin of the Fohns Hopkins Hospital, 106, 81-99.

Ganrot, P. O., and Niléhn, J.-E. (1968). Immunochemical $\omega$ determination of human plasminogen. Clinica Chimcia Acta, 윽 22, 335-340.

Gans, H., and Krivit, W. (1962). Problems in hemostasis $\vec{c}$ during and after open-heart surgery. VI. Over-all changes in blood coagulation mechanism. Fournal of the American Medical Association, 179, 145-147.

Ghosh, M. L., and Emery, J. L. (1973). Hypoxia and asymmetrical fibrosis of the liver in children. Gut, 14, 209-212. $\vec{\varphi}$

Godal, H. C., Abildgaard, U., and Kierulf, P. (1971). The $v$ ethanol test-an indicator of fibrinemia. Coagulation, 3 , 343-345.

Goldschmidt, B. (1970). Effect of vitamin $\mathrm{K}$ on clotting factors in children with congenital cyanotic heart disease. Acta Paediatrica Academiae Scientiarum Hungaricae, 11, 135-139.

Goldschmidt, B., Sarkadi, B., Gárdos, G., and Matlary, A. $\stackrel{\mathbb{\complement}}{\varrho}$ (1974). Platelet production and survival in cyanotic con- $\overrightarrow{\vec{A}}$ genital heart disease. Scandinavian fournal of Haematology, $\frac{\mathrm{O}}{3}$ 13, 110-115.

Gralnick, H. R. (1970). $\epsilon$-aminocaproic acid in preoperative correction of haemostatic defect in cyanotic congenital heart-disaese. Lancet, 1, 1204-1205.

Gross, S., Keefer, V., and Liebman, J. (1968). The platelets in cyanotic congenital heart disease. Pediatrics, 42, 651-658.

Hartmann, R. C. (1952). A hemorrhagic disorder occurring in $\overline{0}$ patients with cyanotic congenital heart disease. Bulletin of 3 the fohns Hopkins Hospital, 91, 49-67.

Hedner, U., Henriksson, P., and Nilsson, I. M. (1975). 윽 Factor XIII in a clinical material. Scandinavian fournal of Haematology, 14, 114-119.

Hedner, U., Nilsson, I. M., and Bergentz, S.-E. (1976). Various prothrombin complex concentrates and their effecto on coagulation and fibrinolysis in vivo. Thrombosis and Haemostasis, 35, 386-395.

Hedner, U., Nilsson, I. M., and Jacobsen, C. D. (1970). Demonstration of low content of fibrinolytic inhibitors in $N$ individuals with high fibrinolytic capacity. Scandinavian N

Fournal of Clinical and Laboratory Investigation, 25, 329-336.
Henriksson, P., and Holmberg, L. (1978). Factor VIII activity and antigen in sick newborns with pathologicako proteolysis in blood. Acta Paediatrica Scandinavica, 67, 83-87.

Holmberg, L., and Nilsson, I. M. (1973). Immunologic studies in haemophilia A. Scandinavian fournal of Haematology, 10, 12-16.

Ihenacho, H. N. C., Breeze, G. R., Fletcher, D. J., and Stuart, $\stackrel{\varrho}{\overparen{D}}$ J. (1973). Consumption coagulopathy in congenital heart- $\mathbb{Q}$ disease. Lancet, 1, 231-234.

Inglis, T. C. McN., Breeze, G. R., Stuart, J., Abrams, L. D., Roberts, K. D., and Singh, S. P. (1975). Excess intravascular coagulation complicating low cardiac output. 
Fournal of Clinical Pathology, 28, 1-7.

Isacson, S., and Nilsson, I. M. (1972). Defective fibrinolysis in blood and vein walls in recurrent "idiopathic" venous thrombosis. Acta Chirurgica Scandinavica, 138, 313-319.

Iölster, N. J. (1970). Blood coagulation in children with cyanotic congenital heart disease. Acta Paediatrica Scandinavica, 59, 551-557.

Johnson, C. A., Abildgaard, C. F., and Schulman, I. (1968). Absence of coagulation abnormalities in children with cyanotic congenital heart-disease. Lancet, 2, 660-662.

Karaca, M., Nilsson, I. M., and Hedner, U. (1971). Quantitative determination of platelet fibrinogen. Fournal of Laboratory and Clinical Medicine, 77, 485-489.

Komp, D. M., and Sparrow, A. W. (1970). Polycythemia in cyanotic heart disease-a study of altered coagulation. Fournal of Pediatrics, 76, 231-236.

Kontras, S. B., Bodenbender, J. G., Craenen, J., and Hosier, D. M. (1970). Hyperviscosity in congenital heart disease. fournal of Pediatrics, 76, 214-220.

Kontras, S. B., Sirak, H. D., and Newton, W. A., Jr. (1966), Hematologic abnormalities in children with congenital heart disease. Fournal of the American Medical Association, 195, 611-615.

Kummer, H., Gurtner, H. P., and Bucher, U. (1964). Thrombocytopenie bei chronischem Cor pulmonale und cyanotischen Herzvitien. Schweizerische medizinische Wochenschrift, 94, 1334-1336.

McFarlane, A. S. (1956). Labelling of plasma proteins with radioactive iodine. Biochemical fournal, 62, 135-143.

McKay, D. G. (1969). Progress in disseminated intravascular coagulation. Part II. California Medicine, 111, 279-290.

Markarian, M., Lindley, A., Jackson, J. J., and Bannon, A. (1967). Coagulation factors in pregnant women and premature infants with and without the respiratory distress syndrome. Thrombosis et Diathesis Haemorrhagica, 17, 585-594.

Maurer, H. M., (1972). Hematologic effects of cardiac disease. Pediatric Clinics of North America, 19, 1083-1093.

Niléhn, J.-E. (1967). Separation and estimation of "split products" of fibrinogen and fibrin in human serum. Thrombosis et Diathesis Haemorrhagica, 18, 487-498.

Nilsson, I. M., Blombäck, M., and Ramgren, O. (1961). Haemophilia in Sweden. I. Coagulation studies. Acta Medica Scandinavica, 170, 665-682.

Nilsson, I. M., Blombäck, M., and von Francken, I. (1957). On an inherited autosomal haemorrhagic diathesis with anti-haemophilic globulin (AHG) deficiency and prolonged bleeding time. Acta Medica Scandinavica, 159, 35-57.

Nilsson, I. M., and Olow, B. (1962). Determination of fibrinogen and fibrinogenolytic activity. Thrombosis et Diathesis Haemorrhagica, 8, 297-310.

Ohshima, N. (1976). Hemorheology in hyper- and hypoviscosity syndrome. Thrombosis Research, 8, Suppl. II, 9-16.

O'Neill, B. J., and Hutton, R. A. (1966). Prolonged bleeding time in congenital heart disease (abstract). Fournal of Clinical Pathology, 19, 99.

Pandolfi, M., Bjernstad, A., and Nilsson, I. M. (1972). Technical remarks on the microscopical demonstration of tissue plasminogen activator. Thrombosis et Diathesis Haemorrhagica, 27, 88-98.

Perlick, E., Ursinus, K., Ursinus, W., and Hofman, G. (1971). Pathogenese, Prophylaxe und Therapie der Blutstillungsstörungen bei kongenitalen Kardiopathien. Zeitschrift für die gesamte innere Medizin, 26, 545-551.

Pike, G. J., Turner, R. L., Manohitharajah, S. M., and Deverall, P. B. (1975). Fibrinolysis in cyanotic and acyanotic children before and after open intracardiac operations with the Bentley Temptrol oxygenator. Fournal of Thoracic and Cardiovascular Surgery, 69, 922-926.

Terplan, K. L. (1973). Patterns of brain damage in infants and children with congenital heart disease. American Fournal of Diseases of Children, 125, 175-185.

Waldman, J. D., Czapek, E. E., Paul, M. H., Schwartz, A. D., Levin, D. L., and Schindler, S. (1975). Shortened platelet survival in cyanotic heart disease. Fournal of Pediatrics, 87, 77-79.

Wedemeyer, A., Edson, R., and Krivit, W. (1972). Coagulation in cyanotic congenital heart disease. American fournal of Diseases of Children, 124, 656-660.

Wedemeyer, A., and Lewis, J. H. (1973). Platelet survival studies in cyanotic cardiac patients (abstract). Fournal of Pediatrics, 83, 161.

Wells, R. E., Jr., Denton, R., and Merrill, D. W. (1961). Measurement of viscosity of biologic fluids by cone plate viscometer. Fournal of Laboratory and Clinical Medicine, 57, 646-656.

Requests for reprints to Dr Per Henriksson, Department of Paediatrics, Allmänna Sjukhuset, S-214 01 Malmö, Sweden. 